\title{
Physician-delivered motivational interviewing to improve adherence and retention in care among challenging HIV- infected patients in Argentina (COPA2): study protocol for a cluster randomized controlled trial
}

Omar Sued $^{1 *} \mathbb{D}$, Isabel Cassetti ${ }^{2}$, Diego Cecchini ${ }^{2}$, Pedro Cahn ${ }^{1}$, Lina Bofill de Murillo ${ }^{3}$, Stephen M. Weiss ${ }^{3}$, Lissa N. Mandell ${ }^{3}$, Manasi Soni ${ }^{3}$ and Deborah L. Jones ${ }^{3}$

\begin{abstract}
Background: "Challenging" HIV-infected patients, those not retained in treatment, represent a critical focus for positive prevention, as linkage to care, early initiation of antiretroviral therapy, adherence and retention in treatment facilitate viral suppression, thus optimizing health and reducing HIV transmission. Argentina was one of the first Latin American countries to guarantee HIV prevention, diagnosis and comprehensive care services, including antiretroviral medication, which removed cost and access as barriers. Yet, dropout occurs at every stage of the HIV continuum. An estimated 110,000 individuals are HIV-infected in Argentina; of these, 70\% have been diagnosed and $54 \%$ were linked to care. However, only $36 \%$ have achieved viral suppression and $31 \%$ of those diagnosed delayed entry to care. To achieve meaningful reductions in HIV infection at the community level, innovative strategies must be developed to re-engage patients. Motivational Interviewing (MI) is a patient-centered approach and has been used by therapists in Central and South America to enhance motivation and commitment in substance use and risk reduction. Our pilot feasibility study utilized culturally tailored $\mathrm{Ml}$ in physicians to target patients not retained in treatment in public and private clinics in Buenos Aires, Argentina. Results demonstrated that a physician-based Ml intervention was feasible and effective in enhanced and sustained patient adherence, viral suppression, and patient-physician communication and attitudes about treatment among these patients at 6 and 9 months post baseline.

Methods/design: This clinical trial seeks to extend these findings in public and private clinics in four urban population centers in Argentina, in which clinics ( $n=6$ clinics, six MDs per clinic site) are randomized to experimental (physician Ml Intervention) $(n=3)$ or control (physician Standard of Care) $(n=3)$ conditions in a 3:3 ratio. Using a cluster randomized clinical trial design, the study will test the effectiveness of a physician-based Ml intervention to improve and sustain retention, adherence, persistence, and viral suppression among "challenging" patients $(n=420)$ over 24 months.

(Continued on next page)
\end{abstract}

\footnotetext{
* Correspondence: omar.sued@huesped.org.ar

${ }^{1}$ Fundación Huésped, Pasaje Angel Peluffo 3932, C1202ABB Buenos Aires,

Argentina

Full list of author information is available at the end of the article
}

(c) The Author(s). 2018 Open Access This article is distributed under the terms of the Creative Commons Attribution 4.0 International License (http://creativecommons.org/licenses/by/4.0/), which permits unrestricted use, distribution, and reproduction in any medium, provided you give appropriate credit to the original author(s) and the source, provide a link to the Creative Commons license, and indicate if changes were made. The Creative Commons Public Domain Dedication waiver (http://creativecommons.org/publicdomain/zero/1.0/) applies to the data made available in this article, unless otherwise stated. 
(Continued from previous page)

Discussion: Results are anticipated to have significant public health implications for the implementation of Ml to re-engage and retain patients in HIV treatment and care and improve viral suppression through high levels of medication adherence.

Trial registration: ClinicalTrials.gov, ID: NCT02846350. Registered on 1 July 2016.

Keywords: Adherence, Retention, HIV, Motivational interviewing, Argentina, Physicians

\section{Background}

"Challenging" patients, those not retained in treatment, represent a critical focus for effective HIV prevention efforts to achieve reduction in overall individual- and community-level viral burden $[1,2]$. These "challenging" patients, here defined as those not retained in care, are often characterized by a lack of medication persistence, defined as obtaining treatment followed by a gap in care [3], inconsistent treatment visits, and repeated missed appointments. Such behavior renders antiretroviral therapy (ART) ineffective and typically results in treatment failure.

Argentina was one of the first Latin American countries to guarantee HIV comprehensive care services, which removed cost and access as barriers to care for HIV-infected patients. Yet, as in the USA, dropout occurs at every stage of the HIV continuum from linkage to retention, prescription and viral suppression. Of the estimated 110,000 HIV-infected individuals in Argentina, $70 \%$ have been diagnosed and $54 \%$ of those eligible (CD4 count $<500$ cells $/ \mathrm{mm}^{3}$ ) were linked to treatment. However, only $36 \%$ achieved viral suppression and $31 \%$ of those diagnosed delayed entry to care $[4,5]$. Patients disengaged from care fail to achieve and maintain the benefits of antiretroviral therapy, such as optimal health and reduced potential for HIV transmission [2].

Ongoing "retention in care" is defined as attending two or more appropriately spaced visits within 1 year with an HIV medical provider [6]. If patients are not retained in care, rapid re-engagement and retention are essential, as achieving viral suppression requires twice as long with suboptimal retention [7]. The Argentina standard of care recommends patients re-engaged in care are evaluated quarterly for viral suppression, or more frequently as needed, for 1-year following relinkage; thereafter, if immunologically stable and virologically suppressed, assessments are biannual. ART prescription refills are almost exclusively provided monthly by physicians; 2-month prescriptions are only provided for special circumstances or for private patients with insurer permission. Theoretically, retention can be enhanced through monitoring and tracking missed appointments, adapting clinic structures and healthcare systems to respond to barriers to care, and providing supportive information, skills and motivation to patients to enable them to navigate the health care system.
Our pilot study, Conexiones y Opciones Positivas en la Argentina (COPA), estimated that retention in care in urban clinics with high HIV rates ranged from 65 to 90\%. Given universal access to care, patients with uncontrolled HIV constitute a significant public health threat due to an increased likelihood of viral resistance [8], treatment failure and HIV transmission; in fact, in $2013,23.8 \%$ of those on medication were already on second-line ART [9]. Clearly, retention in care is a growing challenge to effective HIV treatment. This study addresses re-engagement of patients not retained in care following ART prescription.

Effective strategies to re-engage "challenging" patients must be developed and implemented if we are to achieve meaningful population-level decreases in HIV incidence. Our feasibility study targeting challenging patients was culturally tailored to the local setting and found to be both feasible and highly acceptable to patients, physicians, and clinic staff in public and private clinics in Buenos Aires, Argentina. The study identified barriers in public and private settings that were changed (e.g., systems to reschedule appointments and obtain prescriptions when medical appointments are missed, proximity of laboratory and pharmacy services), but while infrastructure development can facilitate engagement, ultimately patient-centered care relies on the physician-patient relationship [10].

Both physicians and patients were enthusiastic regarding the use of Motivational Interviewing (MI) during clinical consultations, and reported greater patient engagement in treatment. MI is a patient-centered approach and has been used by therapists in Central and South America to enhance motivation and commitment in substance use and risk reduction. Physicians can provide ongoing stimulus to enhance engagement, adherence and long-term retention in care (here defined as adherence to ART and clinical care [11-16]). Patient-centered care has been linked to adherence to treatment, self-management of chronic disease and clinical outcomes in HIV [17] including retention. Improved communication can enhance long-term retention, persistence and adherence, yet physicians may receive only limited training in communication and, once established, communication styles can be difficult to influence [18]. Development of patient-centered communication skills requires supervision [19], but physicians rarely receive feedback after medical school. Thus, MI is more 
often used by therapists or health care staff (e.g., psychologists, counselors, nurses) than physicians (e.g., [20-22]), despite academic literature supporting the utility of MI for HIV-infected patients to address or increase adherence and enhance communication (e.g., [23-28]). Utilizing MI, providers can encourage patients to recognize and overcome barriers to medication adherence and persistence and to take constructive actions, e.g., appointment attendance $[29,30]$. Though used widely in addiction counseling in the US, MI use has been limited among physicians in Spanish-speaking populations (e.g., [31-33]). In addition, few studies have successfully intervened with HIV physicians to enhance physicians' communication style and content while assessing its influence on patient outcomes $[20,24]$. Similarly, few studies have successfully trained physicians to utilize MI to bring about health-behavior change to achieve biomedical outcomes such as viral suppression (e.g., asthma [34]), and other than our pilot study, we are unaware of any studies training physicians to enhance and sustain retention in challenging HIV-infected patients.

In our pilot study, MI was successfully utilized to enhance adherence and engagement in care among challenging patients in public and private health care settings in Buenos Aires, Argentina [35, 36]. Using a full factorial design, the relative benefit of patient and physician interventions in isolation and in combination was compared at 6 and 9 months' follow-up. At 9 months, participants receiving care provided by a physician trained in MI achieved the highest proportion of viral suppression, reported significantly higher adherence and greater satisfaction with their provider relationship and treatment, as compared to those in the physician inactive condition, physician standard of care. Both public and private clinic patients had comparable improvements in adherence, and public and private physicians had comparable improvement in the use of MI-based communication methods. Results demonstrated that infectious disease physicians trained in MI re-engaged patients in care, i.e., enhanced and sustained patient adherence, viral suppression and improved patient-physician communication and treatment attitudes at 6 and 9 months post baseline. Our pilot study also found both patients and physicians preferred a collaborative approach to HIV treatment, one that relied on physician medical expertise and the patient's own experiences [36]. In contrast, providing a group patient intervention increased, but did not sustain, adherence or viral suppression. Results supported the efficacy of a physician-based MI intervention, suggesting that physicians may be optimally positioned to provide ongoing MI-based consultation rather than "single dose" patient-based interventions.

\section{Aim of the study}

This clinical trial (COPA2) proposes to test the impact of the MI intervention in a variety of clinical sites and regions to assess the generalizability and reach of the original findings from our pilot study, and to assess the potential for the physician-based MI intervention to maximize re-engagement and sustain retention, adherence and medication persistence among challenging patients in a broad variety of treatment settings. The current study extends these highly promising findings to six public and private clinics in four urban centers with high HIV prevalence, in which clinics $(n=6)$ are randomized to intervention (physician MI training) $(n=3)$ or standard of care (physician SOC) $(n=3)$ conditions in a 3:3 ratio. Using a cluster randomized clinical trial design, the study will test the effectiveness of MI skill training for physicians $(n=36)$ to re-engage and retain challenging patients $(n=420)$ and improve and sustain retention, adherence, persistence and viral suppression. The physician training in MI has been endorsed by the Argentina Society for Infectious Diseases and Panamerican Association of Infectious Diseases. As such, this study uses a sustainable model for MI training and supervision that can be implemented and disseminated to achieve the maximum public health impact to enhance re-engagement and sustain retention, viral suppression, persistence and adherence among "challenging" patients in HIV care.

\section{Methods/design \\ Objectives}

Study objectives are to (1) evaluate the effectiveness of a physician MI intervention to enhance long-term retention in care, medication adherence, medication persistence, and viral suppression among challenging patients and (2) determine patient- and physician-level factors impacting patient response to the MI intervention.

\section{Setting}

In Argentina, and in much of Latin America, data on retention in care may be unreliable [37]. Earlier studies reported HIV prevalence among sexually transmitted diseases clinic attendees to be $20.4 \%$, and $6.9 \%$ at outpatient clinics [38]. It was estimated that less than $50.0 \%$ of patients in Argentina knew their serostatus [39, 40]. Estimates have predicted that $22.7 \%$ [41] to $35.4 \%$ [39] of patients have AIDS at the time of diagnosis, that $11.9 \%$ of those unaware of their HIV status require treatment, and that mortality increases dramatically if patients are not engaged in care within 5 years of infection [39]. Lastly, structural challenges in over-saturated hospitals have been reported, e.g., long waiting periods to ART initiation caused by legal, financial and laboratory challenges, challenging continuity in care [42]. Late initiation of ART (>6 months post referral) is problematic in many regions of the world [43], including South America.

In Argentina, 31\% of men and 23\% of women entered care late [5]; in Chile, $80 \%$ of patients; and in Peru, $40 \%$ 
[4, 37]. Many HIV-infected patients in Argentina have reported that they are unsure of the potential impact of non-adherence [42, 44], and expressed concern with antiretroviral (ARV) side effects [42] and their impact on social relationships $[44,45]$. Feelings of ambivalence, weariness and anxiety about ART often lead to non-adherence and medication discontinuation [42]. Physicians have expressed frustration with challenging patients and our pilot indicated that clinical interventions are primarily paternalistic $[44,46]$. Studies $[35,42]$ illustrate that increasing engagement in care increases retention and activates patients' involvement in treatment through the formation of a therapeutic alliance with physicians.

\section{Design}

This clinical trial utilizes a cluster randomized design to be conducted over 4 years, testing the effectiveness and long-term sustainability of MI clinical skill training to improve retention, re-engagement, adherence and viral suppression among challenging patients (Additional file 1). Clinics $(n=6)$ were randomized to intervention (physician MI training) $(n=3)$ or control (physician Standard of Care training) $(n=3)$ conditions in a 3:3 ratio. Within each clinic, six physicians $(n=36$ total providers) and 60 patients not retained in care (with an additional 30 transgender patients at two sites) $(n=420$ total patients) will be enrolled. (N.B.: after the study started, the investigators were awarded a supplement to the parent grant to increase the sample size and to include 60 transgender women, given the lack of information on this population and the potential differences in study outcomes. Some aspects of the supplement, such as targeted recruitment methods and separate analytic techniques, differ from the main protocol. This article focuses on the main protocol).

\section{Physicians}

Thirty-six physicians were recruited and trained (three training workshops/presentations conducted over 2 years), and will be assessed semiannually for 2 years (five assessments) at six sites, six physicians per site. Assessments address professional and general demographics (e.g., clinical experience, training, age), along with standard of care practices. Training is either on (1) Motivational Interviewing (intervention) or (2) Optimizing Entry, Retention and Adherence (control). All physicians complete audio/video recordings of one patient consultation with a COPA2-enrolled patient semiannually (five recordings). Physicians receiving Motivational Interviewing training receive online video supervision on MI implementation (coaching calls with an MI trainer) as reviewed in their videos at 3 months post MI training, 3 months-post advanced MI training, and at 12 months post baseline (approximately $30 \mathrm{~min}$ per supervision session). For this reason, each physician in the intervention group records one additional video after the first MI training workshop to enable them to receive feedback on their MI implementation.

\section{Patients}

Four hundred and twenty patients will be recruited and assessed for 2 years (five assessments), from six sites, 60 patients per site, with two sites including an additional 30 transgender patients each. Assessments will address patient demographic characteristics, adherence, depression, self-efficacy, communication with physician, and drug and alcohol use. Participants will provide two hair samples, at the 12-month and 24-month assessments. If viral load is not available through clinic records, patients will be asked to provide a blood sample for viral load assessment. A subset of participants will participate in audio/video recording of a consultation with their physician (who is also participating in the study) for MI supervision of physicians; patients at each site are randomized to be selected for audio/video recording. All patient participants will provide consent for medical record abstraction to assess clinic/laboratory visits, viral load results, and pharmacy fills.

Clinic randomization was conducted by generating a list of random numbers assigning clinics to condition. Clinics were assigned to numbers by staff not associated with the study; the US statistician was blind to clinic numbering and conducted randomization by number at study onset. Clinics were randomized to offer physicians $(n=36)$ either (1) the intervention condition: three training sessions in MI or (2) the control condition: three time-matched video-delivered sessions on Entry to Care, Retention and Adherence. Both conditions were time matched and all participants attend a total of five assessments (baseline, 6, 12, 18 and 24 months post intervention). Patients participating in this study $(n=420)$ within each clinic ( $n=60$ per clinic, with an additional 30 transgender participants per clinic at two clinic sites) are randomly assigned to be audio/video recorded at a regularly occurring consultation with their physician (who is participating in the study). Patients and physicians are assessed at 6-month intervals for 24 months, enabling a two-group (MI Intervention, Control SOC) $\times$ five timepoints (Baseline, 6 months, 12 months, 18 months, 24 months) comparison.

\section{Study hypotheses \\ Hypotheses 1.1-1.3}

A higher proportion of patients from clinics offering the physician MI intervention will be retained in care, maintain optimal medication adherence, and achieve viral suppression at $6,12,18$, and 24 months post baseline, as compared to those from clinics offering the control condition standard of care. 


\section{Hypothesis 1.4}

Patients from clinics offering the physician MI intervention will be more likely to maintain medication persistence throughout the 2-year study period as compared to those from clinics offering the control condition standard of care.

\section{Hypothesis 2.1-2.3}

Within the MI condition, increased implementation of MI strategies by physicians will be associated with increased likelihood of their patients being retained in care, maintaining optimal medication adherence, and achieving an undetectable viral load.

\section{Hypothesis 2.4}

Within the MI condition, greater self-efficacy, motivation, and higher satisfaction with the patient-physician relationship will be associated with increased likelihood of being retained in care, maintaining medication adherence, and achieving an undetectable viral load.

\section{Principles for recruitment Inclusion criteria}

The study will increase the reach of the pilot study and increase its generalizability, expanding the patient population to public and private clinic and hospital patients, including transgender women, drug users, men who have sex with men (MSM), and heterosexual men and women. All eligible participants (patients, physicians) will be enrolled and assessed over 24 months.

Patients Eligible individuals will be $\geq 18$ years of age and "challenging" HIV-infected patients, (1) diagnosed for $>6$ months and having a recent (i.e., $\leq 3$ months) detectable viral load $>500$ copies $/ \mathrm{mL}$ following 6 months of ART prescription and (2) not retained in care, i.e., three missed pharmacy pick-ups in the last six consecutive months, or not attending a physician visit in the last 12 months or more. Patient participants will be recruited within participating clinics; clinic records will be reviewed to identify potential candidates. There are no exclusions based on literacy, as all materials will be administered using an audio computer-assisted self-interview system (ACASI) supervised by assessors.

This study will recruit HIV-infected men, women and transgender women, targeting subgroups of heterosexual women, men who have sex with men, drug users, sex workers, and transgender women, and representative of the ethnic subgroups. This study will collaborate with the Association of Transvestites, Transsexuals, and Transgender of Argentina (ATTTA) to enhance recruitment of transgender women. Patient participants will be men, women and transgender persons recruited from four urban areas in Argentina: Buenos Aires city, Rosario,
Cordoba and Neuquén. The racial/ethnic demographic of this region is diverse, but primarily Caucasian with a small percentage of Indigenous peoples. Therefore, this study will enroll individuals of all ethnicities. The inclusion of women is an integral component of the study. Women comprised almost half of the HIV-infected participants at the clinical sites and this study will reflect a similar demographic. The study will recruit individuals of less than 21 years of age and the minimum age for inclusion is 18 years of age. (Patients aged under 18 years will not be included as Argentine law requires that HIV+ individuals aged under 18 years are under parental supervision and World Health Organization (WHO) guidelines require differing doses of medication for those aged under 18 years). Contacting patients and getting them into the clinic is the first step in re-engagement; pilot study results illustrated a spike in adherence following recruitment and enrollment among control condition participants, which was not sustained over time in the control condition. In both conditions, study retention will be also enhanced by compensation for assessments and coordination with physician/laboratory appointments.

Physicians Eligible physicians will be infectious disease physicians drawn from participating sites, $n=6$ per site. Each site had a minimum of six physician candidates available to enroll; participating clinics have an average of 6-10 physicians on staff. While we do not anticipate dropout (Argentine physicians are less likely to leave or change clinics), additional physicians are available to participate and staff members will track physicians moving to new sites who wish to continue to participate.

\section{Recruitment}

Patient participants $(n=60$ per site, with an additional 30 transgender participants per site at two clinics) will be recruited from six clinic sites, both private and public clinics. These clinics serve representative populations of HIV patient groups (e.g., MSM, intravenous drug users (IDU), heterosexuals, transgender, sex workers) and report ongoing HIV screening and diagnosis of new patients each week, and significant numbers of patients lost to care each year, ranging from 5 to $35 \%$, representing an adequate patient sample for the study. Study recruiters at all sites were clinic counselors and administrative staff; recruiters were requested to identify patients who were not attending regular consultations in the last year (more than 3 months since the last expected visit). Each clinic will contact patients to return to the clinic, and returning patients will be invited to participate. Patients at participating clinics will be informed about the study by the study recruiters and those interested in enrollment will be referred to study staff. Persons contacting the outreach workers (who will be available in the clinics) on their own initiative will be 
asked for minimal demographic information to determine whether the patient meets basic inclusion and exclusion criteria. Those who meet these criteria will be given a detailed description of the study procedures, including time requirements and procedures to maintain confidentiality and will be scheduled for an orientation session, at which time they will be further informed about the study and asked to provide signed Informed Consent. Each qualified participant will then be scheduled for a baseline assessment (baseline questionnaires, and, if not available from medical records, a blood sample for viral load assessment). Given the time demands of this study and the personal nature of disclosures required we will be offering each participant monetary compensation for sessions (approximately US\$10 per session). Study staff will conduct recruitment at the sites and will provide ongoing oversight of participant retention using patient locator data and rapid follow-up for missed appointments.

Physicians at clinics will be briefed on the study in a presentation by the coinvestigators, and invited to participate. Those interested in participating will be referred to on-site study staff and be given a detailed description of the study procedures, including time requirements and procedures to maintain confidentiality.

We have found that retention of patient participants who may be progressing in disease status presents special problems for which alternative procedures are required to maximize retention. As noted, we will compensate participants for their time, and will coordinate assessments with physician visits or pharmacy visits when possible. Our previous study indicated that increased retention is possible through concerted follow-up contacts and involvement of study staff. We propose to train staff to maintain continuing contact with study participants throughout the 24-month period of the study. Tracking methods will include collecting detailed locator information at baseline (e.g., address, two contact persons, home landmarks, workplace) as well as maintaining contact currency by updating and verifying locator information and telephone contacts at each subsequent visit. The staff members will make regular attempts to locate missing participants over a 2-week period following failure to present for an appointment. If, over a period of 2 weeks of continued attempts, we are unable to reach a participant for scheduling an assessment, we will seek to complete the assessment over the phone if possible or visit the contact person(s) that participants provided at study entry to learn of the whereabouts of the participant, or send a telegram. The study staff will be responsible for coordinating follow up and ensure confidentiality is maintained when making contacts in the community.

We have found that clinics may experience staff turnover in a 4-year period. To remain enrolled in the study, physicians must be seeing patients at the participating clinic. Participating physicians will have regular contact (quarterly) with trainers and other participating physicians. Staff members will maintain contact information to facilitate tracking, should physicians fail to present for scheduled appointments. (N.B.: in Argentina, physicians rotating/transferring to alternate facilities while participating in studies have the option to continue to provide care to study participants for the duration of the study. Alternatively, physicians may choose to discontinue their participation when transferring. In such cases, an additional physician will be recruited at the site if possible, and provided with training.)

\section{Site selection}

To obtain sufficient numbers of challenging patients from the general patient population, participants $(n=60$ per site, with an additional 30 transgender participants per site at two clinics) will be recruited from six public and private clinic sites. Most HIV-infected persons (83\%) live in the province of Buenos Aires, Buenos Aires city, and within the provinces of Córdoba, Santa Fe and Mendoza; the epidemic is specifically urban. In 2015, the COPA team conducted a survey of 16 clinic and hospital sites in four urban centers with the highest HIV prevalence, Buenos Aires, Rosario, Cordoba and Neuquén, to assess willingness and interest in participating in the clinical trial. Of the 16 sites surveyed, 10 sites met the eligibility criteria for participation in the clinical trial; (1) willing to participate, (2) adequate HIV-patient load, (3) adequate numbers of patients meeting lost to follow-up criteria (see "Principles for recruitment - Patients" above) each year, (4) adequate numbers of interested infectious disease physicians (minimum of six per site). Sites selected expressed strong support for the implementation and objectives of the clinical trial. Clinics serve representative populations of HIV patient groups (e.g., MSM, IDU, transgender, women) and report ongoing HIV screening and diagnosis of new patients weekly at each site, representing an adequate patient population for the study. Clinic staff at all clinics include retention specialists who will track patients lost to care, and all clinics have similar retention strategies, including surveillance to contact patients who miss appointments, assessment of psychosocial needs and provision of referrals, updating patient contact information, and flexible hours. Participating clinics have an average of 6-10 physicians on staff and at least six of these physicians were interested in participating, representing adequate numbers of physicians available for study participation.

\section{Randomization}

Cluster randomization at the clinic level is utilized to reduce the potential for contamination within clinics, i.e., exposing control patients to providers who received MI 
training, accommodating for the "natural" clustering of patients within physicians. (N.B.: as it is anticipated that some COPA2 patients will occasionally be seen by non-participating physicians not trained in MI, the study will track whether patients are seen by non-participating physicians. However, in order to comply with the protocol, each patient will be scheduled to see a COPA2 physician at least once every 6 months). Clinic randomization was conducted by generating a list of random numbers assigning clinics to condition. Both public and private clinics are included as representative of the Argentine health care system; clinics were matched by public/private and HIV census prior to randomization.

\section{Intervention}

\section{Motivational Interviewing (MI) - theoretical model}

The original MI model arose from the client-centered therapy skill of "accurate empathy" [47], and focused on responding differentially to client speech, within an empathic client-centered style. MI emphasizes two components: a "relational component" that relies on empathy and the "interpersonal spirit of MI" (collaboration between patient and physician) and a "technical component" that involves the evocation and reinforcement of patient "change talk" (communication indicative of consideration of behavior change). MI is best described as targeting ambivalence regarding health-behavior change, in this context, adherence to clinical care and medication regimens. In addressing ambivalence, the physician evokes and strengthens the patient's verbalized motivation to change ("change talk") to develop a plan and commitment to change. In doing so, self-efficacy and motivation to change are increased, resulting in enhanced health behavior, i.e., treatment adherence and medication persistence, and ultimately resulting in enhanced health outcomes, i.e., viral suppression. The provider seeks to have the patient, rather than the provider, voice their own arguments for positive change [48], e.g., reasons to increase their engagement in care.

\section{Training physicians and health care staff (nurses, reception staff, peer health navigators)}

The intervention training utilizes a structured, sustainable MI training and supervision program designed to improve retention, adherence and persistence in challenging patients. While there is some controversy over the "best" MI training strategy (e.g., [49]), the current MI training applies recommendations from our feasibility study, recommendations from previous studies (e.g., [23, 49]) and guidance from our expert consultant, Dr. Carolina Yahne, for (1) sensitization training for front-line staff on the clinic as a motivational setting, (2) increased physician training time to four half days over 2 weeks at baseline, 6 (advanced) and 12 months (refresher), (3) long-distance
Skype supervision for physicians at each site to be conducted 3 months post baseline, 6 and 12 months' training using coded video recordings of clinical consultations, (4) establishment of sustainable training for local physicians providing HIV healthcare and sustainable local supervisors/supervision for physicians. While our pilot study did not experience problems in physician retention, yearly training opportunities will be provided for new physicians replacing those who may leave the study. All training, supervision and implementation will be led by MI trainers, with support from the senior US investigators. Dr. Yahne has co-authored numerous articles and textbooks with Dr. William Miller and others on Motivational Interviewing as a clinical strategy in both English and Spanish, and co-produced video training materials in English and Spanish. Dr. Yahne has trained clinicians and providers in English and Spanish in the US, Central and South America, and is the founder of the Motivational Interviewing Network of Trainers (MINT). This study focuses on the providers with the greatest referent power in Argentina, physicians, while providing sensitization focus group training for front-line staff (reception, counselors, nursing) focusing on the clinic environment as a motivational setting.

\section{MI physician intervention}

Intensive training will take place three times in the first 2 years and utilize Motivational Interviewing, $3 r d E d$. Spanish [50]; training interventions will be delivered in four half-day sessions over 2 weeks. The Provider Training Intervention Manual and accompanying slide presentations were developed collaboratively by the COPA team with input from Dr. Yahne. The training elements will address the basic MI skills and elements identified as most effective [23], MI spirit (collaboration, evoking patient motivation, honoring patient autonomy [48]), recognizing and reinforcing change talk, and "rolling" with (not fighting) resistance (MI consistency). Physicians utilizing MI will learn to engage with patients in an empathic, nonjudgmental manner and to pose simple but strategic questions to motivate change; when patients resist change, the physician learns to "roll" with resistance instead of confronting it. If and when the patient is ready to initiate a change, the physician will be prepared to support their decision [36]. Training will utilize baseline and follow-up patient-physician videotapes to enable physicians to individually review their own patient interactions independently, focusing on $\mathrm{MI}$, communication strategies and opportunities to respond more accurately to patient communication. Advanced and refresher training after 6 and 12 months will utilize the same training structure and providing additional supervision and feedback.

\section{MI supervision}

Training will be followed by individual supervision and feedback for physicians using audio/video recordings 
and Skype consultations to promote fidelity to MI. Supervision will be provided by MI trainers on Skype at 3 months post MI training, 3 months post advanced MI training and at 12 months, approximately $30 \mathrm{~min}$ per supervision session. During the training, Argentine trainers (Drs. Lucas and Bordatto) and the US trainer (Dr. Bofill) from our pilot study will be trained by MI trainers to develop a sustainable training and supervision program. (N.B. Should a physician withdraw from the study, the sustainable training and supervision model will enable COPA2 to recruit, train and supervise additional physicians wishing to participate in the study].

\section{Standard of care (SOC) condition}

SOC site physicians will attend three time-matched video presentations over 2 years on research on optimizing entry into and retention in care and adherence, from training materials available from Fundación Huésped.

\section{Assessment measures}

Patient and Physician Measures were selected from the pilot study, based on patient, physician and clinic characteristics relevant to study outcomes. Measures were in Spanish and adapted to the local context during the pilot study or were used for general reference, adapted, translated, back translated and reviewed for fit with cultural and local context. Assessments are administered via audio computer-assisted self-interview (ACASI) to minimize the influence of social desirability and improve data quality. Study staff introduce the ACASI system to ensure participant competence and are available for assistance during the assessment. Patient assessments at baseline and 24 months are approximately $60 \mathrm{~min}$; physician ACASI assessments are approximately $20 \mathrm{~min}$. Figure 1 illustrates the schedule for enrollment, interventions, and assessments. All sites schedule clinical appointments quarterly (3-monthly) for patients failing treatment (not engaged, detectable viral load, calendar year $1)$; after 1 year and with undetectable viral load, patients are scheduled biannually (6-monthly, calendar year 2). Pharmacy pick-up is scheduled monthly for all patients; those with long-term, undetectable viral load can arrange for bimonthly pick up only with special permission.

\section{Clinical outcomes: baseline, semiannual assessment for 2 years (five assessments)}

HIV Viral Load (VL): patients should have been prescribed 6 months of ART and have a recent (i.e., $\leq 3$ months) detectable VL $>500$ copies $/ \mathrm{mL}$ as eligibility criteria. HIV VL are performed at least every 6 months on all patients as standard of care; data will be abstracted from medical records; if not available, VL will be assessed by blood sampling. Viral suppression (HIV VL $<200$ copies/mL) will be the primary dichotomous outcome; a secondary dichotomization will be made among detectable patients with $\mathrm{VL}<1000$ and those with VL $>1000$ [51, 52]).

\section{Behavioral outcomes: baseline, semiannual assessment for 2 years (five assessments)}

Outcomes are retention in care, medication persistence, and ART adherence. In this study, retention in care will be defined as the number of missed clinic appointments (i.e., "no shows" not canceled in advance by patients or clinic staff) in the 6 months preceding assessment, including that timepoint's visit with the COPA2 physician. The primary retention analysis will utilize a dichotomized indicator $0 / 1$ of any missed visits vs. no missed visits, and the missed appointment count will also be used to create a continuous appointment adherence percentage variable (number of completed visits/number scheduled [53, 54]). All patients will have at least one scheduled appointment per 6 months so the $0 / 1$ variable will be valid for all patients. The proportion of kept appointments includes the total number as the denominator; thus, it corrects for inflated numbers of missed appointments. Medication persistence will be measured by the time to treatment discontinuation, with a permissible gap of $<30$ days [3]; participants will be considered to have discontinued the regimen if a therapy gap $\geq 30$ days occurs. This will be measured by monthly pharmacy pick-ups; failure to obtain a month's medication will indicate a 30-day gap in therapy. Measures are adapted from the HIV/AIDS Bureau Performance Measures guidelines [55] obtained by medical record abstraction. Adherence will be measured by hair sample, pharmacy pick-ups (monthly), and self-report. Hair sample will estimate an average concentration of ARV medication exposure over 6 weeks with cut-off values used as categorical variables (12 months and 24 months) [56, 57]. Self-report will reflect percentage adherent over the last 30 days (Visual Analog Scale; VAS); responses are integer values from 0 to 10 , which represent percentage of doses taken (0-100) when multiplied by 10 .

\section{MI patient targets: baseline, semiannual assessment for 2 years (five assessments)}

Self-efficacy The HIV Treatment Adherence Self-Efficacy Scale (HIV-ASES [58]) will assess the patients' perceived self-efficacy in being adherent.

Motivation for adherence Motivation for adherence will be measured using the LifeWindows InformationMotivation-Behavioral Skills Adherence Assessment Questionnaire [59], a 10-item measure on motivation to be adherent. Items use a 5-point range - strongly disagree to strongly agree.

Patient-physician communication/treatment The Prerana Interview [60] will be used to assess the 


\begin{tabular}{|c|c|c|c|c|c|c|}
\hline & \multirow[b]{2}{*}{ Procedures and Instruments } & \multicolumn{5}{|c|}{ Timepoint } \\
\hline & & Baseline & 6 months & 12 months & 18 months & 24 months \\
\hline \multirow[t]{2}{*}{ Recruitment } & Eligibility screen & $\mathrm{X}$ & - & - & - & - \\
\hline & Informed consent & $\mathrm{X}$ & - & - & - & - \\
\hline \multirow[t]{2}{*}{ Interventions } & MI Training or SOC Training & $\mathrm{X}$ & $\mathrm{X}$ & $\mathrm{X}$ & - & - \\
\hline & $\begin{array}{l}\text { MI Supervision - Coaching calls } \\
\text { with MDs (MI group only) }\end{array}$ & 3 months & 9 months & $\mathrm{x}$ & - & - \\
\hline Clinical Outcomes & Viral load & $\mathrm{x}$ & $\mathrm{x}$ & $\mathrm{x}$ & $\mathrm{x}$ & $\mathrm{x}$ \\
\hline \multirow[t]{5}{*}{ Behavioral outcomes } & Lab/MD Appointment & $\mathrm{x}$ & $\mathrm{x}$ & $\mathrm{X}$ & $\mathrm{X}$ & $\mathrm{X}$ \\
\hline & $\begin{array}{l}\text { Attendance/Retention in care } \\
\text { (Medical records) }\end{array}$ & $x$ & $\mathrm{x}$ & $\mathrm{x}$ & $\mathrm{x}$ & $x$ \\
\hline & $\begin{array}{l}\text { Pharmacy pick up (monthly; } \\
\text { Pharm. Records) }\end{array}$ & $\mathrm{x}$ & $x$ & $x$ & $x$ & $x$ \\
\hline & Adherence: Hair sample & - & - & $\mathrm{x}$ & - & $\mathrm{x}$ \\
\hline & $\begin{array}{l}\text { Adherence: Visual Analogue } \\
\text { Scale (VAS } 30 \text { days) }\end{array}$ & $x$ & $x$ & $x$ & $x$ & $x$ \\
\hline \multirow[t]{3}{*}{ MI Patient targets } & $\begin{array}{l}\text { Patient Motivation } \\
\text { (LifeWindows) }\end{array}$ & $x$ & - & - & - & $\mathrm{x}$ \\
\hline & Patient Self Efficacy (HIV-ASES) & $\mathrm{x}$ & $\mathrm{x}$ & $\mathrm{x}$ & $\mathrm{x}$ & $\mathrm{x}$ \\
\hline & $\begin{array}{l}\text { Patient - Physician } \\
\text { Communication /Treatment } \\
\text { Attitudes (Prerana Interview) }\end{array}$ & $\mathrm{X}$ & $\mathrm{x}$ & $\mathrm{x}$ & $\mathrm{x}$ & $\mathrm{x}$ \\
\hline \multirow[t]{3}{*}{ Physician MI targets } & $\begin{array}{l}\text { MI Skills (pre-post training - MI } \\
\text { group only) (Helpful Responses } \\
\text { Questionnaire) }\end{array}$ & $\mathrm{x}$ & $\mathrm{x}$ & $\mathrm{x}$ & - & - \\
\hline & $\begin{array}{l}\text { MI Implementation (Videos, } \\
\text { Coded Skills) (MITI) }\end{array}$ & $x$ & $x$ & $x$ & $x$ & $x$ \\
\hline & $\begin{array}{l}\text { MI Supervision \& Training Scale } \\
\text { (MISTS) }\end{array}$ & $x$ & $x$ & $x$ & & \\
\hline \multirow[t]{6}{*}{ Control variables } & $\begin{array}{l}\text { Beck Depression Inventory (BDI- } \\
\text { II) }\end{array}$ & $\mathrm{x}$ & - & $x$ & - & $\mathrm{x}$ \\
\hline & Drug abuse screen (DAST-10) & $x$ & - & $\mathrm{x}$ & - & $\mathrm{x}$ \\
\hline & $\begin{array}{l}\text { Alcohol Use Disorders Ident. } \\
\text { Test (AUDIT) }\end{array}$ & $x$ & - & $X$ & - & $X$ \\
\hline & Patient Demographics & $\mathrm{x}$ & - & - & - & - \\
\hline & $\begin{array}{l}\text { Physician } \\
\text { Demographics/Training }\end{array}$ & $x$ & - & - & - & - \\
\hline & Clinic SOC Checklist & $X$ & - & $\mathrm{x}$ & - & $\mathrm{X}$ \\
\hline
\end{tabular}


patient-provider relationship and attitudes towards treatment. Items include psychosocial barriers to patientprovider communication and clinic appointment attendance and attitudes regarding treatment.

\section{MI physician targets: baseline, semiannual assessment for 2 years (five assessments)}

MI pre-post workshop skills The Helpful Responses Questionnaire [61] is a qualitative tool used to assess MI skills and will be administered pre and post MI workshop training.

MI implementation skills Audio/video recording review, Motivational Interviewing Treatment Integrity (MITI) Version 2.0 [62] coding system of videotaped interviews every 6 months (five recordings) with COPA2-enrolled patients. Patients will be participants randomized at a regular visit for audio/video recording; for each physician, at each timepoint, the patient they are to record the video with will be randomly selected from their assigned COPA2 patients. Each patient will not be selected for more than one video; therefore, this will comprise a representative sample of the patient participants.

Motivational Interviewing Supervision and Training Scale (MISTS) This is a physician/therapist checklist of quantity and quality of each MI strategy, completed by the physician following the session, and reviewed by the trainer.

\section{Control variables: baseline and semiannual assessment for 2 years (five assessments)}

Depression The Beck Depression Inventory-II (BDI-II [63], Spanish) measures somatic and non-somatic symptoms of depression separately to distinguish the manifestation of depression from symptoms of HIV, which may resemble depression in some cultures.

Drug abuse The Drug Abuse Screening Test-10 (DAST-10 [64], adapted, Spanish) will assess the risk of abuse of illegal or prescription drugs and is a 10-item measure assessing the use of drugs, excluding alcohol and tobacco, which is responded using a dichotomous (yes/no) response.

Alcohol use The Alcohol Use Disorders Identification Test (AUDIT [65], Spanish) is a 10-item assessment of indices of alcohol consumption (i.e., frequency, binge drinking, alcohol-related problems).

Patient demographics Assessment includes gender identity, age, income, housing, education and HIV history, e.g., time since diagnosis, time on ART, past HIV care, barriers to care.

Physician demographics Assessment includes clinical experience, training, and age.

Clinic characteristics Standard of care practice at each clinic [66] is evaluated as a checklist completed by the physician participants. The scores from each site's physicians will be pooled to yield an average score from each clinic.

\section{Consortium, staff training and quality assurance}

The University of Miami and Argentina investigators have bi-weekly conference calls to review all aspects of study implementation including the recruitment, enrollment, assessments, training, quality control and conformity to the project timeline. The PI provides overall leadership and ensure fidelity to protocol and the Argentina investigators provide direct oversight and guidance for all phases of implementation at their sites. Training manuals for the interventions were developed by the US and Argentina teams in English, translated into Spanish and back-translated into English for fidelity. All new translations (e.g., informed consents) were conducted under the supervision of the Argentina PIs. Staff training for assessments and the MI intervention were conducted on site by Drs. Jones, Bofill and Weiss and Argentina MI trainers. Team members from the Fundación Huésped site will receive guidance in the use of hair-sampling analysis under the supervision of Dr. Gandhi at UCSF. Ongoing quality assurance to ensure fidelity of the intervention to the study protocol is provided by the Argentina PIs and project coordinator; a sample of $10 \%$ of audio/video-recorded MI-patient sessions are reviewed by Dr. Bofill. Data managers from both the USA and Argentina teams will review physical health and pharmacy pick-up data, which will be obtained from medical records and entered into REDCap (Research Electronic Data Capture) online databases [67] (see also "Assessment measures").

\section{Dissemination and implementation}

Study results will be disseminated to regional sites by the study team. Dr. Cahn, co-investigator from Fundación Huésped, is past President of the International AIDS Society, and will, together with Drs. Sued and Cassetti, lead the dissemination of the study results. If successful, the Society of Infectious Disease and the Panamerican Association of Infectious Diseases have provided strong endorsement for a training program for infectious disease physicians and the training team will collaborate on dissemination and implementation. 


\section{Analysis approach}

Prior to primary and secondary analyses, potential demographic confounders will be tested for association with outcome variables and for imbalance between groups. If significant, these variables will be controlled in the final models. All analyses will include random terms to account for repeated measures as well as the nesting of patients within providers and the clinic-randomized design. Random-effects models [68] will be used to incorporate the nested data structure (the nesting of patients within providers). This study will use an intention-to-treat analysis. Due to the relatively small number of randomized clusters, experimental and control groups will be carefully examined for imbalance on key covariates prior to analyses. Heterogeneity between clinics and clinicians will be described by random effects in the analyses. Potential covariates include clinic standard of care, patient and physician demographics (e.g., income, training), patient depression and substance use. To adjust for inflated type I errors due to multiple comparisons, Bonferroni corrections [69] will be used for $p<.05$. For analyses that involve viral loads, it is expected that there will be some missing cases of this key outcome variable. We expect that the majority of missing viral load results will be due to the participant missing a clinic visit. To control for effects of potential variables that systematically influence missing cases, the dichotomous retention variable (no missed visits vs. at least one missed visit) will be included as a covariate in the hypothesized model; all coefficients will be estimated. In addition, missing data patterns will be analyzed for viral loads using Little's missing completely at random (MCAR) test [70]. If the $p$ value for the MCAR is not significant, then missingness is assumed to be missing at random (MAR [70]), which allows for the use of full-information maximum likelihood (FIML) estimation [71] to handle missing cases.

\section{Hypotheses 1.1-1.3}

A higher proportion of patients from clinics offering the physician MI intervention will be retained in care, maintain optimal medication adherence, and achieve viral suppression at $6,12,18$, and 24 months post baseline, as compared to those from clinics offering the standard of care.

\section{Hypothesis 1.4}

Patients from clinics offering the physician MI intervention will be more likely to maintain medication persistence throughout the 2-year study period as compared to those from clinics offering the standard of care.

\section{Analytic strategy 1.1-1.3}

To evaluate hypotheses 1.1-1.3, two analyses will be conducted for each outcome. The first "unadjusted" analysis will include time, randomized condition, and the interaction between time and condition as predictors, and conditions will be compared at each timepoint. The interaction between time and condition will be examined due to the results of the pilot study; initial improvements were present in both the control and experimental groups, but they were not sustained over time in the control group. In addition to these primary predictors, the second "adjusted" analysis will include time-varying measurements of self-efficacy, depression and substance use as covariates. To incorporate repeated binary outcomes (retention in care and viral suppression) over five timepoints (baseline, 6, 12, 18, and 24 months), generalized linear mixed models [72] will be used. Hypotheses 1.1 and 1.3 will be evaluated utilizing repeated measures logistic regression models. The proportion of patients retained in care (i.e., those having no missed clinic appointments in the previous 6 months) and those achieving an undetectable viral load will be compared between the experimental and control groups at $6,12,18$, and 24 months post baseline using the fitted model. Hypothesis 1.2 will utilize a similar analytic strategy, except it will use a linear mixed model [68] to examine percentage adherence in the past 30 days as a continuous outcome. Furthermore, to estimate unbiased parameters, we will check the normality assumption for this adherence outcome by using skewness and kurtosis (acceptable range $= \pm 2$ ) [73]. If the variable will not hold the normality assumption, the outcome will be a logarithm.

\section{Analytic strategy 1.4}

Hypothesis 1.4 will be evaluated using a frailty model, which is an extension of the Cox regression model to include random effects. Time to discontinuation of medication regimen (in months) will be the outcome of interest, and the hazard ratio for discontinuation will be computed for the experimental vs. the control condition. Additional analyses will adjust for time-varying covariates as above.

\section{Hypotheses 2.1-2.3}

Within the MI condition, increased implementation of MI strategies by physicians will be associated with increased likelihood of their patients being retained in care, maintaining optimal medication adherence, and achieving an undetectable viral load.

\section{Hypothesis 2.4}

Within the MI condition, greater self-efficacy, motivation and higher satisfaction with the patient-physician relationship will be associated with increased likelihood of being retained in care, maintaining medication adherence, and achieving an undetectable viral load. 


\section{Analytic strategy 2.1-2.4}

Hypotheses 2.1-2.4 will be evaluated utilizing unadjusted and adjusted analyses, similarly to hypotheses 1.1-1.4. For each outcome, the first analysis will include only the primary predictors, and the second will adjust for psychosocial covariates. Hypotheses 2.1-2.3 will be analyzed using similar strategies as hypotheses 1.1-1.3 but restricted to patients in the MI group. The primary predictors of interest in each analysis will be time $(6,12,18$, and 24 months), physician implementation of MI (a count variable indicating the number of times MI strategies were used during videotaped patient encounters in the 6 months preceding assessment), and the interaction between implementation and time. The $F$ statistic for the type III test of the interaction term will be examined; if significant, slopes will be estimated between implementation and outcome variables at each timepoint. If the $F$ statistic is not significant, the model will be refit including only main effects of time and implementation, and the slope for implementation will be evaluated (testing a relationship between implementation and outcomes that is not time-dependent). Hypothesis 2.4 will be evaluated in a similar manner as hypotheses 2.1-2.3; the primary predictors of interest will be time, self-efficacy, motivation and patient-provider relationship. A model including a full-factorial combination of all predictors will be fit and reduced to a final model utilizing an appropriate model selection strategy (e.g., backwards elimination). Two exploratory analyses will also be conducted: the first will explore how successfully the implementation of MI is sustained over time by utilizing a Poisson regression with implementation as the count outcome and time as the predictor of interest. The second will be a series of analyses similar to those utilized for hypotheses 2.1-2.3 including physician characteristics (e.g., years of training) as predictors of patient outcomes. In order to determine which components of the intervention were most effective in promoting positive patient outcomes, the final set of analyses will examine skills targeted by the MI intervention (both patient-level, e.g., motivation and self-efficacy and provider level, e.g., implementation of MI) as potential mediators of patient outcomes. Data will be incorporated into time-lagged path models in which we will test the hypothesis that exposure to the MI training/exposure to physicians trained in MI will result in increases in these skills over time, which will be related to subsequent improvements in patient outcomes (e.g., higher rates of viral suppression) (Table 1).

\section{Power analysis}

The effect size assumed in the power calculation is from the pilot data, which is the "gold standard" for power calculations; the calculation is done for the primary aim - viral suppression, as we sought to power for the most important outcome. The sample size for this study was determined according to data gathered by the COPA pilot; $68 \%$ of patients in the experimental group achieved viral suppression by 9-month follow-up as opposed to $44 \%$ of those in the control condition. Assuming a similar effect size will be observed in this larger trial and that the plausible range of viral suppression is 20 to $60 \%$ in the control group, a power analysis indicates that six clinics allocated in a 3:3 ratio with six providers and 60 patients per clinic (excluding transgender patients) will provide $>80 \%$ power to detect a difference between groups using a two-tailed test at $\alpha=.05$. This analysis also assumes $60 \%$ of the variance will be between providers within clinics and $40 \%$ will be between clinics.

\section{Sources of material - data collection}

Biological, psychosocial and behavioral data will be collected during the study via clinic medical records, computer assisted interviews and hair and/or blood sampling. Physical health and pharmacy pickup data will be obtained from clinic/pharmacy records and entered into REDCap, a secure web-based database application [67]. Hair sample (100 hairs) will be used to assess concentrations of antiretroviral medication at 12 months and 24 months. If no viral load sample is available within the previous 3 months, a blood sample $(1 \times 10 \mathrm{~mL})$ will be collected to assess viral load; when available, existing VL samples drawn within an appropriate sampling frame will be used instead of additional blood draw. The standard of care at all clinics is VL assessment every 3 months for patients not virally suppressed or retained in care; study assessments will utilize existing VL when visits are aligned with study time points. Computer-assisted assessments will be overseen at the sites by trained study staff. Laboratory data will be collected by trained clinic phlebotomists. Data will be coded with ID numbers only, and linkage data will be stored separately for tracking. No unique identifiers will be maintained with the samples or together with the data; access to collected data will be restricted to study staff only. The following procedures will be used for biological materials: viral load testing will be conducted at each clinic. The interviewer will complete a form providing information on the participant (study number, date, name of test, interviewer); the patient will provide a blood sample and a copy of the request will be returned to the participant record in the respective study office. The original forms will be left with the phlebotomist and the blood sample and form will be transferred to the clinic laboratory for testing. Hair sample collection requires a pair of scissors used to collect $\sim 100$ hairs near the scalp, samples are wrapped in foil and stored at room temperature. Hair can be stored for long periods prior to analysis and will be shipped to the US lab without precautions for biohazardous materials. Demographic data and psychosocial 


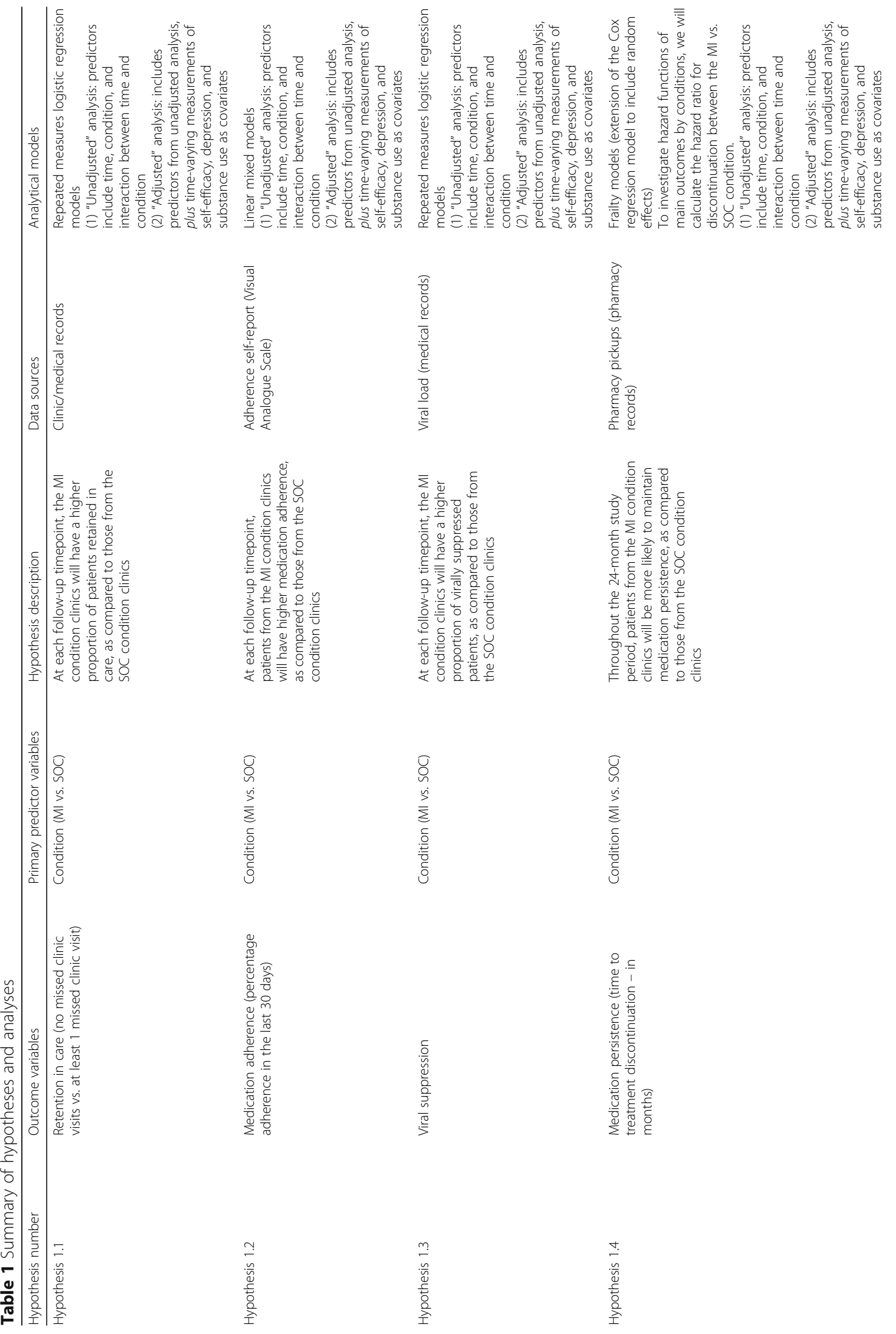




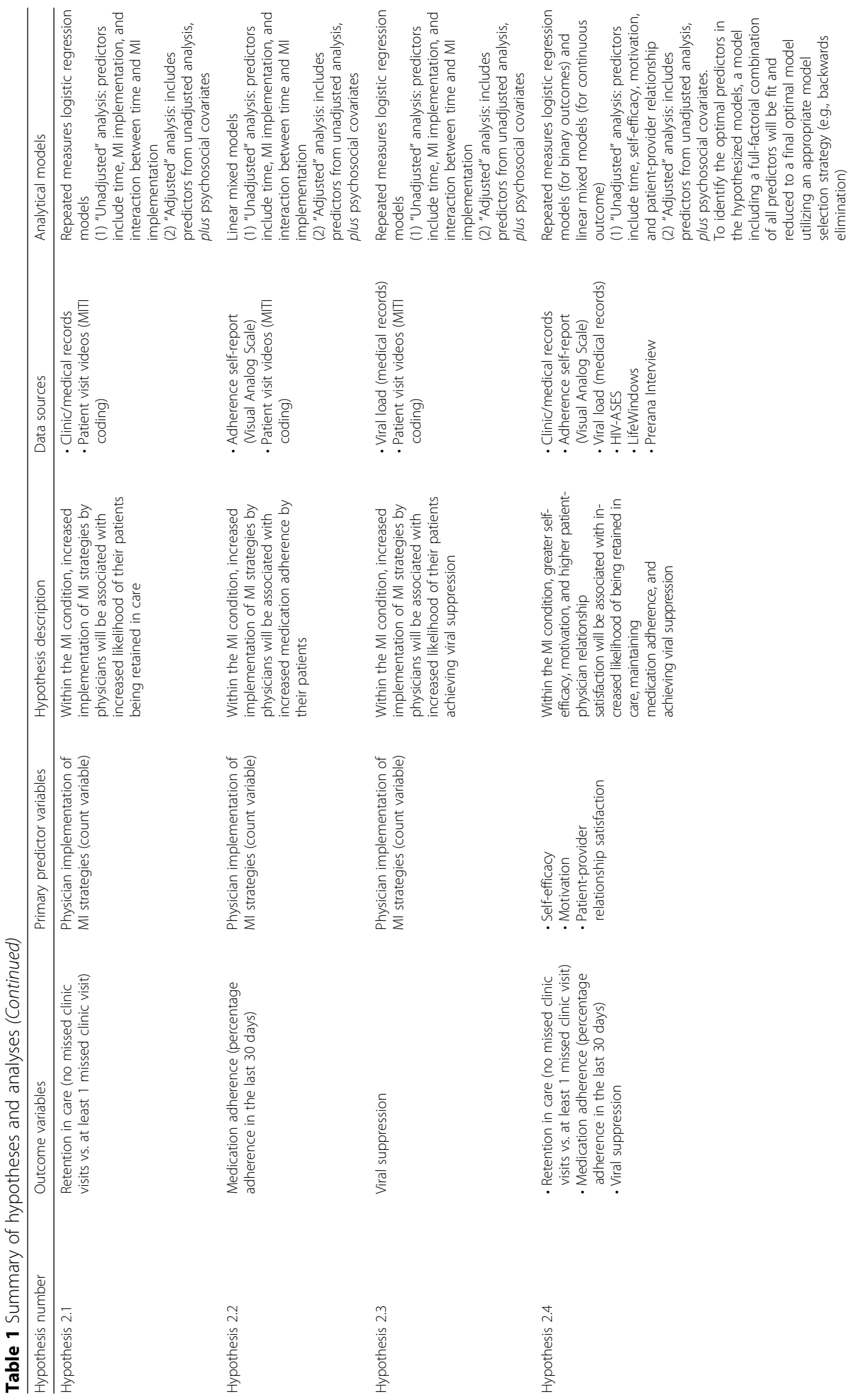




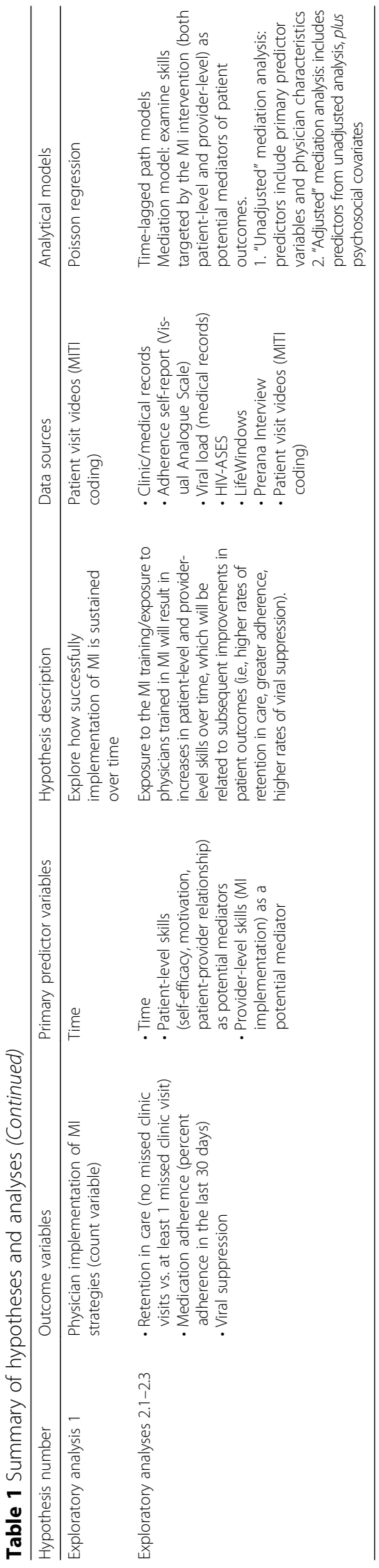


data collected during the study via computer-assisted interviews will be uploaded to a secure cloud storage system. MI implementation data will be obtained from audio/videotaped consultations with patients, in which the physician is viewed and the patient is obscured from view and identification.

\section{Data safety and monitoring}

A Data Safety Monitoring Board (DSMB) has been established to provide monitoring of the experimental arm at study midpoint to determine: (1) if there are any unexpected systematic variations in health status attributable to either study condition which may be negatively affecting the health of the participants; and (2) whether the intervention condition (or control) are demonstrating such clear-cut positive effects that continuation of the trial (i.e., withholding the treatment from the SOC control condition) would be considered unethical. Monitors will periodically review and evaluate the accumulated study data for participant safety, study conduct and progress, and efficacy, and make recommendations concerning the continuation, modification, or termination of the trial. The DSMB will consider study-specific data as well as relevant background knowledge about the disease or patient population under study. The DSMB defined event triggers that would call for an unscheduled review, stopping guidelines, unmasking (unblinding) and voting prior to initiating data review. The DSMB is also responsible for maintaining the confidentiality of its internal discussions and activities as well as the contents of reports provided to it. Prior to study onset, the DSMB will review the protocol for major concerns. The DSMB consists of three monitors who are independent expert investigators in HIV research not associated with the study.

During the trial of COPA2, the DSMB will review cumulative study data to evaluate safety, study conduct, and scientific validity and integrity of the trial. DSMB members must be satisfied that the timeliness, completeness, and accuracy of the data submitted to them for review are sufficient for evaluation of the safety and welfare of study participants. The DSMB should also assess the performance of overall study operations and any other relevant issues, as necessary.

\section{Adverse events}

Given the behavioral nature of this study, adverse events are not anticipated, but a response plan has been developed, following institutional policy guidelines. In accordance with the plan, the PI will report all adverse events in writing to the University of Miami's Institutional Review Board (IRB) within two working days of the PI learning of the event. Drs. Sued, Cahn and Cassetti, the co-PIs in Argentina, will also report adverse events in the same manner to the Argentina Ethics Committees.
This same procedure is also applicable should the PI learn of a participant's death during their enrollment.

Non-serious adverse events will be reported in writing to the UM IRB at the time of continuing or final review of the study protocol; the Argentina Ethics Committees associated with the site and the primary subcontractor will be informed of non-serious adverse events during their normal reporting cycles. Reporting of both serious and non-serious adverse events to the boards of UM and Argentina are carried out via standardized forms that detail the date, nature, relationship to research and result/ status of each event.

\section{Discussion}

This study addresses several priority topics of research: retention and engagement in HIV services, achievement of optimal prevention, and treatment responses among people who are living with HIV. Results from the pilot study identified the elements of the MI intervention, patient self-efficacy and motivation, and facilitating patientprovider partnerships and communication, which were associated with patient engagement and underlay the intervention outcome, viral suppression. Study results may have significant public health implications for the implementation of MI to re-engage and retain patients in HIV treatment and care and improve viral suppression through high levels of medication adherence. The study approach is designed to enhance dissemination and proposes to establish a sustainable MI training and supervision program for physicians which, if successful, can be implemented and disseminated in public and private health care settings, which are representative of the HIV healthcare delivery system in Argentina.

\section{Trial status}

Interested physicians were identified prior to study start; physicians were officially recruited and enrolled between October 2016 to March 2017. Patient enrollment began November 2016 and is expected to be completed in April 2018. The trial is expected to end in May 2020.

\section{Additional file}

Additional file 1: SPIRIT 2013 Checklist: recommended items to address in a clinical trial protocol and related documents. (DOC $123 \mathrm{~kb}$ )

\section{Abbreviations}

ACASI: Audio computer-assisted self-interview; ART: Antiretroviral therapy; ARV: Antiretrovirals; ATTTA: Association of Transvestites, Transsexuals, and Transgender of Argentina; AUDIT: Alcohol Use Disorders Identification Test; BDI-II: Beck Depression Inventory-Il; COPA: Conexiones y Opciones Positivas en la Argentina (Positive Connections in Argentina); COPA2: Conexiones y Opciones Positivas en la Argentina 2 (Positive Connections in Argentina 2); DAST-10: Drug Abuse Screening Test-10; DSMB: Data Safety Monitoring Board; FIML: Full-information maximum likelihood; HIV-ASES: HIV Treatment Adherence Self-Efficacy Scale; IDU: Intravenous drug users; IRB: Institutional 
Review Board; MAR: Missing at random; MCAR: Missing completely at random; MI: Motivational Interviewing; MINT: Motivational Interviewing Network of Trainers; MISTS: Motivational Interviewing Supervision and Training Scale; MITI: Motivational Interviewing Treatment Integrity; MSM: Men who have sex with men; REDCap: Research Electronic Data Capture; SOC: Standard of Care; VAS: Visual Analogue Scale; VL: Viral load; WHO: World Health Organization

\section{Acknowledgements}

We thank all the members of the COPA study team, as well as the medica providers and patients, without whom this study would not be possible.

\section{Funding}

This study was funded by the National Institute of Mental Health, R01MH1 10242, with support from the University of Miami Center for AIDS Research, National Institute of Allergies and Infectious Diseases, P30AI073961. Funding sources had no role in the study design, and will not have any role in data collection, management, analysis, or interpretation; the decision to submit results; or writing or submitting manuscripts for publication.

\section{Disclaimer}

The views expressed in this article are those of the authors and are not official positions of the University of Miami Miller School of Medicine, Fundación Huésped, Fundación Helios Salud, or the National Institute of Mental Health.

\section{Authors' contributions}

OS, IC, PC, LB, SMW, and DJ conceptualized the pilot study upon which the present study is based. OS, IC, DC, PC, LB, SMW, and DJ designed the pilot study and adapted it into the present study. LM, MS, LB, OS, and DJ drafted the manuscript, with contributions from all authors. All authors read and approved the final manuscript.

\section{Ethics approval and consent to participate}

All human subject activities are conducted through clinics in Argentina. Prior to the initiation of the study, the University of Miami's Institutional Review Board (IRB) approval was obtained (ID: 20160313), and Argentina IRBs associated with the clinic sites also reviewed the study for approval prior to any human subject activities. Study staff completed human research participation training and good clinical practice training. Each participant must sign a written informed consent prior to enrollment.

\section{Consent for publication}

Not applicable

\section{Competing interests}

The authors declare that they have no competing interests.

\section{Publisher's Note}

Springer Nature remains neutral with regard to jurisdictional claims in published maps and institutional affiliations.

\section{Author details}

${ }^{1}$ Fundación Huésped, Pasaje Angel Peluffo 3932, C1202ABB Buenos Aires, Argentina. ${ }^{2}$ Helios Salud, Peru 1515, Buenos Aires, Argentina. ${ }^{3}$ Department of Psychiatry and Behavioral Sciences, University of Miami Miller School of Medicine, 1400 NW 10th Ave, Miami, FL, USA.

Received: 31 July 2017 Accepted: 25 June 2018 Published online: 24 July 2018

\section{References}

1. Montaner JS, Lima VD, Barrios R, Yip B, Wood E, Kerr T, Shannon K, Harrigan PR, Hogg RS, Daly P, Kendall P. Association of highly active antiretroviral therapy coverage, population viral load, and yearly new HIV diagnoses in British Columbia, Canada: a population-based study. Lancet. 2010;376:532-9.

2. The White House. Executive order-HIV care continuum initiative. 2013. https://obamawhitehouse.archives.gov/the-press-office/2013/07/15/ executive-order-hiv-care-continuum-initiative.
3. Cramer JA, Roy A, Burrell A, Fairchild CJ, Fuldeore MJ, Ollendorf DA, Wong PK. Medication compliance and persistence: terminology and definitions. Value Health. 2008;11:44-7.

4. Crabtree-Ramirez B, Caro-Vega Y, Shepherd BE, Wehbe F, Cesar C, Cortes C, Padgett D, Koenig S, Gotuzzo E, Cahn P, et al. Cross-sectional analysis of late HAART initiation in Latin America and the Caribbean: late testers and late presenters. PLoS One. 2011;6:e20272.

5. Ministerio de Salud de la Nación. Boletín N³1 sobre el VIH-SIDA en la Argentina. (Publication 31 on HIV/AIDS in Argentina). Dirección de Sida y ETS, Ministerio de Salud de la Nación. Año XVII. 2014. http://www.msal.gob. ar/images/stories/bes/graficos/0000000601cnt-2015-01-29_boletinepidemiologico-vih-2014.pdf.

6. HRSA (Health Resources and Services Administration) - HIV/AIDS Bureau Outreach: engaging people in HIV care, Summary of a HRSA/HAB 2005 consultation on linking PLWH into care. 2006. https:/careacttarget.org/sites/ default/files/file-upload/resources/hivoutreachaug06.pdf.

7. Crawford TN, Sanderson WT, Thornton A. Impact of poor retention in HIV medical care on time to viral load suppression. J Int Assoc Provid AIDS Care. 2014;13:242-9.

8. Pando MA, Gomez-Carrillo M, Vignoles M, Rubio AE, dos Ramos Farias MS, Vila M, Rossi D, Ralon G, Marone R, Reynaga E, et al. Incidence of HIV type 1 infection, antiretroviral drug resistance, and molecular characterization in newly diagnosed individuals in Argentina: A Global Fund Project. AIDS Res Hum Retrovir. 2011;27:17-23.

9. Caldas de Mesquita F, Pascom ARP, Habckost Dutra de Barros C, Machado Givisiez J, dos Santos Christ MT, de Faro Valverde L, Araújo de Freitas M. Keynote lecture - Cascade of continuous care in Brazil: present and future challenges. J Int AIDS Soc. 2014;17(Suppl 1):1.

10. Levinson W, Lesser CS, Epstein RM. Developing physician communication skills for patient-centered care. Health Aff (Millwood). 2010;29:1310-8.

11. Mugavero MJ, Norton WE, Saag MS. Health care system and policy factors influencing engagement in HIV medical care: piecing together the fragments of a fractured health care delivery system. Clin Infect Dis. 2011;52(Suppl 2):S238-46.

12. Knowlton AR, Arnsten JH, Eldred $\sqcup$, Wilkinson JD, Shade SB, Bohnert AS, Yang C, Wissow LS, Purcell DW. Antiretroviral use among active injection-drug users: the role of patient-provider engagement and structural factors. AIDS Patient Care STDs. 2010;24:421-8.

13. Bodenlos JS, Grothe KB, Whitehead D, Konkle-Parker DJ, Jones GN, Brantley PJ. Attitudes toward health care providers and appointment attendance in HIV/AIDS patients. J Assoc Nurses AIDS Care. 2007;18:65-73.

14. Wilson IB, Laws MB, Safren SA, Lee Y, Lu M, Coady W, Skolnik PR, Rogers WH. Provider-focused intervention increases adherence-related dialogue but does not improve antiretroviral therapy adherence in persons with HIV. J Acquir Immune Defic Syndr. 2010;53:338-47.

15. Thrun M, Cook PF, Bradley-Springer LA, Gardner L, Marks G, Wright J, Wilson TE, Quinlivan EB, O'Daniels C, Raffanti S, et al. Improved prevention counseling by HIV care providers in a multisite, clinic-based intervention: positive STEPs. AIDS Educ Prev. 2009;21:55-66.

16. Preau M, Leport C, Villes V, Michelet C, Collin F, Carrieri MP, Ragnaud JM, Taieb A, Raffi F, Spire B, Anrs Co-Aproco Study Group. Prevalence and predictors of deterioration of a trustful patient-provider relationship among HIV-infected persons treated with antiretroviral therapy. J Acquir Immune Defic Syndr. 2008:47:467-71.

17. Gerbert B, Danley DW, Herzig K, Clanon K, Ciccarone D, Gilbert P, Allerton M. Reframing "prevention with positives": incorporating counseling techniques that improve the health of HIV-positive patients. AIDS Patient Care STDs. 2006:20:19-29.

18. Laws MB, Beach MC, Lee Y, Rogers WH, Saha S, Korthuis PT, Sharp V, Wilson IB. Provider-patient adherence dialogue in HIV care: results of a multisite study. AIDS Behav. 2013;17:148-59.

19. Tongue JR, Epps HR, Forese LL. Communication skills for patient-centered care-research-based, easily learned techniques for medical interviews that benefit orthopaedic surgeons and their patients. J Bone Joint Surg Am. 2005;87a:652-8.

20. Flickinger TE, Rose G, Wilson IB, Wolfe H, Saha S, Korthuis PT, Massa M, Berry S, Laws MB, Sharp V, et al. Motivational interviewing by HIV care providers is associated with patient intentions to reduce unsafe sexual behavior. Patient Educ Couns. 2013;93:122-9.

21. Rubak S, Sandbaek A, Lauritzen T, Borch-Johnsen K, Christensen B. General practitioners trained in motivational interviewing can positively affect the attitude to behaviour change in people with type 2 diabetes. One year follow-up of an RCT, ADDITION Denmark. Scand J Prim Health Care. 2009;27:172-9. 
22. Van Voorhees BW, Fogel J, Pomper BE, Marko M, Reid N, Watson N, Larson J, Bradford N, Fagan B, Zuckerman S, et al. Adolescent dose and ratings of an Internet-based depression prevention program: a randomized trial of primary care physician brief advice versus a motivational interview. J Cogn Behav Psychother. 2009;9:1-19.

23. Apodaca TR, Longabaugh R. Mechanisms of change in motivational interviewing: a review and preliminary evaluation of the evidence. Addiction. 2009;104:705-15.

24. Beach MC, Roter DL, Saha S, Korthuis PT, Eggly S, Cohn J, Sharp V, Moore $\mathrm{RD}$, Wilson IB. Impact of a brief patient and provider intervention to improve the quality of communication about medication adherence among HIV patients. Patient Educ Couns. 2015;98:1078-83.

25. Hill S, Kavookjian J. Motivational interviewing as a behavioral intervention to increase HAART adherence in patients who are HIV-positive: a systematic review of the literature. AIDS Care. 2012;24:583-92.

26. Konkle-Parker DJ, Erlen JA, Dubbert PM, May W. Pilot testing of an HIV medication adherence intervention in a public clinic in the Deep South. J Am Acad Nurse Pract. 2012;24:488-98.

27. Parsons JT, Rosof E, Punzalan JC, Di Maria L. Integration of motivational interviewing and cognitive behavioral therapy to improve HIV medication adherence and reduce substance use among HIV-positive men and women: results of a pilot project. AIDS Patient Care STDs. 2005;19:31-9.

28. Parsons JT, Golub SA, Rosof E, Holder C. Motivational interviewing and cognitive-behavioral intervention to improve HIV medication adherence among hazardous drinkers-A randomized controlled trial. J Acquir Immune Defici Syndr. 2007:46:443-50.

29. Colby SM, Monti PM, Tevyaw TO, Barnett NP, Spirito A, Rohsenow DJ, Riggs S, Lewander W. Brief motivational intervention for adolescent smokers in medical settings. Addict Behav. 2005;30:865-74.

30. Ogedegbe G, Chaplin W, Schoenthaler A, Statman D, Berger D, Richardson T, Phillips E, Spencer J, Allegrante JP. A practice-based trial of motivational interviewing and adherence in hypertensive African Americans. Am J Hypertens. 2008;21:1137-43.

31. Yahne CE, Miller WR, Irvin-Vitela L, Tonigan JS. Magdalena Pilot Project: motivational outreach to substance abusing women street sex workers. J Subst Abus Treat. 2002;23:49-53.

32. Balan IC, Moyers TB, Lewis-Fernandez R. Motivational pharmacotherapy: combining motivational interviewing and antidepressant therapy to improve treatment adherence. Psychiatry. 2013;76:203-9.

33. Lewis-Fernandez R, Balan IC, Patel SR, Sanchez-Lacay JA, Alfonso C, Gorritz M, Blanco C, Schmidt A, Jiang HP, Schneier F, Moyers TB. Impact of motivational pharmacotherapy on treatment retention among depressed Latinos. Psychiatry-Interpersonal Biol Processes. 2013;76:210-22.

34. Broers S, Smets E, Bindels P, Evertsz FB, Calff M, de Haes H. Training general practitioners in behavior change counseling to improve asthma medication adherence. Patient Educ Couns. 2005;58:279-87.

35. Jones DL, Sued O, Cecchini D, Bofill L, Cook R, Lucas M, Bordato A, Cassetti I, Cahn P, Weiss SM. Improving adherence to care among "hard to reach" HIV-infected patients in Argentina. AIDS Behav. 2016;20:987-97.

36. Bofill L, Weiss SM, Lucas M, Bordato A, Dorigo A, Fernandez-Cabanillas G, Aristegui I, Lopez M, Waldrop-Valverde D, Jones D. Motivational interviewing among HIV health care providers: challenges and opportunities to enhance engagement and retention in care in Buenos Aires, Argentina. J Int Assoc Provid AIDS Care. 2015;14:491-6.

37. Pineirua A, Sierra-Madero J, Cahn P, Guevara Palmero RN, Martinez Buitrago E, Young B, Del Rio C. The HIV care continuum in Latin America: challenges and opportunities. Lancet Infect Dis. 2015;15:833-9.

38. Griemberg G, Bautista CT, Pizzimenti MC, Orfus G, Alonso B, Fernandez T, Cando O, Martinez Peralta L. High prevalence of syphilis-HIV co-infection at four hospitals of the city of Buenos Aires, Argentina. Rev Argent Microbiol. 2006:38:134-6

39. Dilernia DA, Mónaco DC, Krolewiecki A, César C, Cahn P, Salomón H. La importancia del diagnóstico temprano en la supervivencia de los pacientes HIV positivos. MEDICINA (Buenos Aires). 2010;70:453-6.

40. Ministerio de Salud - Presidencia de la Nación. Boletín sobre el VIH-SIDA en la Argentina. Ministerio de Salud - Presidencia de la Nación. 2008.

41. AIDS Coordination of Government of the City of Buenos Aires. Infosida Edición N ${ }^{\circ}$ 5. 2006. http://www.buenosaires.gob.ar/sites/gcaba/files/infosida5.pdf.

42. Colautti MA. Las personas que viven con VIH/SIDA y su vínculo con los antirretrovirales provistos por el Programa Nacional en Argentina. Ciên Saúde Colet. 2012;17:1203-13.
43. Nachega JB, Morroni C, Zuniga JM, Schechter M, Rockstroh J, Solomon S, Sherer R. HIV treatment adherence, patient health literacy, and health care provider-patient communication: results from the 2010 AIDS Treatment for Life International Survey. J Int Assoc Physicians AIDS Care (Chic). 2012;11:128-33.

44. Bofill LM, Lopez M, Dorigo A, Bordato A, Lucas M, Cabanillas GF, Sued O, Cahn P, Cassetti I, Weiss S, Jones D. Patient-provider perceptions on engagement in HIV care in Argentina. AIDS Care. 2014;26:602-7.

45. Jones D, Cook R, Cecchini D, Sued O, Bofill L, Weiss S, Waldrop-Valverde D, Lopez MR, Spence A. Examining adherence among challenging patients in public and private HIV Care in Argentina. AIDS Behav. 2015;19:1619-29.

46. Aristegui I, Dorigo A, Bofill L, Bordatto A, Lucas M, Cabanillas GF, Sued O, Cahn P, Cassetti I, Weiss S, Jones D. Barriers to adherence and retention in public and private healthcare according to patients and health workers. Actual SIDA Infectol. 2014;22:71-80

47. Rogers CR. A theory of therapy, personality, and interpersonal relationships: as developed in the client-centered framework. New York: McGraw-Hill; 1959.

48. Rollnick S, Miller WR. What is motivational interviewing? Behav Cogn Psychother. 1995;23:325-34.

49. Soderlund LL, Madson MB, Rubak S, Nilsen P. A systematic review of motivational interviewing training for general health care practitioners. Patient Educ Couns. 2011:84:16-26.

50. Miller W, Rollnick S. La entrevista motivacional. Barcelona: Paidos Iberica; 2015.

51. Larbalestier N, Mullen J, O'Shea S, Cottam F, Sabin CA, Chrystie AL, Welche J, Zuckerman M, Hay P, Rice $P$, et al. Drug resistance is uncommon in pregnant women with low viral loads taking zidovudine monotherapy to prevent perinatal HIV transmission. AIDS. 2003;17:2665-7.

52. Panel on Treatment of HIV-Infected Pregnant Women and Prevention of Perinatal Transmission. Recommendations for use of antiretroviral drugs in pregnant HIV-1-infected women for maternal health and interventions to reduce perinatal HIV transmission in the United States. Department of health and human services. 2015. http://aidsinfo.nih.gov/contentfiles/ Ivguidelines/PerinatalGL.pdf. Accessed 13 July 2015.

53. Mugavero MJ, Davila JA, Nevin CR, Giordano TP. From access to engagement: measuring retention in outpatient HIV clinical care. AIDS Patient Care STDs. 2010;24:607-13.

54. Mugavero MJ, Westfall AO, Zinski A, Davila J, Drainoni ML, Gardner LI, Keruly JC, Malitz F, Marks G, Metsch L, et al. Measuring retention in HIV care: the elusive gold standard. J Acquir Immune Defic Syndr. 2012;61:574-80.

55. Health Research and Services Administration. HIV/AIDS Bureau (HAB) Performance Measures. US Department of Health and Human Services; 2013. http://hab.hrsa.gov/deliverhivaidscare/coremeasures.pdf. Accessed 10 Aug 2015.

56. Gandhi M, Ameli N, Bacchetti P, Gange SJ, Anastos K, Levine A, Hyman CL, Cohen $M$, Young M, Huang $Y$, et al. Protease inhibitor levels in hair strongly predict virologic response to treatment. AIDS. 2009;23:471-8.

57. Gwadz M, Cleland CM, Applegate E, Belkin M, Gandhi M, Salomon N, Banfield A, Leonard N, Riedel M, Wolfe H, et al. Behavioral intervention improves treatment outcomes among HIV-infected individuals who have delayed, declined, or discontinued antiretroviral therapy: a randomized controlled trial of a novel intervention. AIDS Behav. 2015;19:1801-17.

58. Johnson MO, Neilands TB, Dilworth SE, Morin SF, Remien RH, Chesney MA. The role of self-efficacy in HIV treatment adherence: validation of the HIV treatment adherence self-efficacy scale (HIV-ASES). J Behav Med. 2007;30:359-70.

59. The LifeWindows Project Team. The LifeWindows Information Motivation Behavioral Skills ART Adherence Questionnaire (LW-IMB-AAQ). Storrs: Center for Health, Intervention, and Prevention, University of Connecticut; 2006.

60. Ekstrand ML, Chandy S, Heylen E, Steward W, Singh G. Developing useful highly active antiretroviral therapy adherence measures for India: the Prerana study. J Acquir Immune Defic Syndr. 2010;53:415-6.

61. Miller WR, Hedrick KE, Orlofsky DR. The Helpful Responses Questionnaire: a procedure for measuring therapeutic empathy. J Clin Psychol. 1991;47:444-8.

62. Moyers T, Martin T, Manuel J, Miller W, Ernst D. The motivational interviewing treatment integrity MITI code. Version 2.0. Albuquerque: University of New Mexico, Center on Alcoholism. Substance Abuse and Addictions (CASAA); 2003.

63. Beck AT, Steer RA, Brown GK. Beck Depression Inventory-II (BDI-II). San Antonio: Psychological Corporation; 1996. 
64. Bohn M, Babor T, Kranzler H. Validity of the Drug Abuse Screening Test (DAST-10) in inpatient substance abusers. Probl Drug Depend. 1991;119:233-5.

65. Saunders JB, Aasland OG, Babor TF, de la Fuente JR, Grant M. Development of the Alcohol Use Disorders Identification Test (AUDIT): WHO Collaborative Project on Early Detection of Persons with Harmful Alcohol Consumption-II. Addiction. 1993;88:791-804.

66. de Bruin M, Viechtbauer W, Hospers HJ, Schaalma HP, Kok G. Standard care quality determines treatment outcomes in control groups of HAART-adherence intervention studies: implications for the interpretation and comparison of intervention effects. Health Psychol. 2009;28:668-74.

67. Harris PA, Taylor R, Thielke R, Payne J, Gonzalez N, Conde JG. Research electronic data capture (REDCap) - a metadata-driven methodology and workflow process for providing translational research informatics support. J Biomed Inform. 2009:42:377-81.

68. Raudenbush S, Bryk A. Hierarchical linear models: applications and data analysis methods. Thousand Oaks: Sage; 2002

69. Hochberg Y. A sharper Bonferroni procedure for multiple tests of significance. Biometrika. 1988;75:800-2.

70. Little RJA. A test of missing completely at random for multivariate data with missing values. J Am Stat Assoc. 1988;83:1198-202.

71. Enders CK. Applied missing data analysis. New York: Guilford; 2010.

72. Breslow NE, Clayton DG. Approximate inference in generalized linear mixed models. J Am Stat Assoc. 1993;88:9-25.

73. George D, Mallery M. SPSS for Windows Step by Step: A Simple Guide and Reference, 17.0 update. 10a ed. Boston: Pearson; 2010.

Ready to submit your research? Choose BMC and benefit from:

- fast, convenient online submission

- thorough peer review by experienced researchers in your field

- rapid publication on acceptance

- support for research data, including large and complex data types

- gold Open Access which fosters wider collaboration and increased citations

- maximum visibility for your research: over $100 \mathrm{M}$ website views per year

At BMC, research is always in progress.

Learn more biomedcentral.com/submissions 